\title{
Chronic low back pain patients' use of, level of knowledge of and perceived benefits of complementary medicine: a cross-sectional study at an academic pain center
}

\author{
Julie Dubois ${ }^{1 *}$ (D), Emmanuelle Scala ${ }^{2}$, Mohamed Faouzi ${ }^{1}$, Isabelle Decosterd ${ }^{2}$, Bernard Burnand ${ }^{1}$
} and Pierre-Yves Rodondi ${ }^{1}$

\begin{abstract}
Background: Chronic pain patients often use complementary medicine (CM) to alleviate their pain; however, little is known about the use of CM by chronic low back pain (CLBP) patients. We investigated the frequency of use of CM by CLBP patients, the perceived effects of these therapies, patients' knowledge regarding CM, and patientphysician communication regarding $\mathrm{CM}$.

Method: A cross-sectional survey was conducted from November 2014 to February 2015. A questionnaire was distributed by physicians to 238 consecutive patients consulting for CLBP at the Pain Center of Lausanne University Hospital, Switzerland. Poisson regression model was used to analyze patients' level of knowledge regarding various CMs, and the logistic regression model was used to assess CM use for CLBP.

Results: The questionnaire was returned by 168 CLBP patients (response rate: 70.6\%). Lifetime prevalence of CM use for CLBP was $77.3 \%$. The most commonly used therapies were osteopathy (48.8\%), massage (45.2\%) and acupuncture (31.6\%), rated for their usefulness on a 0-10 scale as a mean \pm SD of $5.4 \pm 2.7,5.9 \pm 2.5$ and $3.8 \pm 3.2$, respectively. The CM treatment best known by patients was osteopathy, followed by massage and acupuncture. If their doctors proposed CM as a treatment for $\mathrm{CLBP}, 78 \%$ of participants reported being very or somewhat likely to try $\mathrm{CM}$. Respondents with $\mathrm{CM}$ health insurance were more likely to use CM $(\mathrm{OR}=2.26 ; 95 \% \mathrm{Cl}$ : 1.07-4.78; $p=0.031)$ for CLBP. Respondents having experienced $C L B P$ for more than five years were more likely to use $C M$ to treat their $C L B P$ than respondents having experienced $\mathrm{CLBP}$ for one year or less ( $\mathrm{OR}=2.84 ; 95 \% \mathrm{Cl}$ : 1.02-7.88; $p=0.044)$.
\end{abstract}

Conclusions: More than three-quarters of CLBP patients in our sample did use CM to treat their CLBP. The results showed that the most commonly used therapies were not necessarily the highest rated in terms of perceived usefulness. These results highlight the importance of developing integrative pain centers in which patients may obtain advice regarding CM treatments.

Keywords: Chronic pain, Back pain, Complementary medicine, Communication

\footnotetext{
* Correspondence: Julie.Dubois@chuv.ch

${ }^{1}$ Institute of Social and Preventive Medicine (IUMSP), Lausanne University

Hospital, Route de la Corniche 10, 1010 Lausanne, Switzerland

Full list of author information is available at the end of the article
} 


\section{Background}

In Western countries, low back pain is one of the most common patient complaints. In the US, the annual prevalence of back pain ranges from 15 to $45 \%$ [1], and back pain is the second most common reason for ambulatory care visits [2]. In Europe, the global prevalence of low back pain was estimated to be $13 \%$ for males and $10 \%$ for women in 2010 [3]. In Switzerland, $47 \%$ of women and 39\% of men suffered from diverse back problems during the four weeks preceding a survey conducted in 2007 [4]. According to Wieser [5], "low back pain (LBP) is a leading cause of reduced work performance and disability" in Switzerland. Low back pain is known to be at high risk of becoming chronic [6]. The overall prevalence of chronic pain in the European population is estimated at $19 \%$, and nearly half of those patients suffer from chronic back pain [7]. A study conducted in North Carolina (US) showed a significant increase in the prevalence of chronic low back pain (cLBP) over a 14-year period, from 3.9\% in 1992 to $10.2 \%$ in 2006 [8].

Because chronic pain is difficult to manage, patients often turn to complementary medicine (CM) to treat or alleviate their discomfort [9]. In the case of chronic low back pain, a systematic review showed that most pharmacological treatments had only a limited impact on pain relief and function improvement [10]. This, and the side effects pharmacological treatments may have, could be a reason why cLBP patients chose to try complementary medicine therapies $[11,12]$. CM use could also be linked to cLBP patients seeking an active role in their treatments and thus turning to $\mathrm{CM}$ as a complement to conventional treatments $[9,12]$. In the US, $52 \%$ of patients with chronic pain claimed to use or have used CM [9], and back pain is the most commonly reported condition in the use of CM [13]. One US study evaluating CM use among CLBP patients revealed that most patients had used chiropractic $(45 \%)$ or massage (21\%) for their back pain [14]. Some CM therapies, such as acupuncture, have been shown to be moderately effective in the treatment of low back pain $[10,15,16]$. In Switzerland, 25\% of the population aged 15 or older had used at least one type of CM during the previous 12 months [17], and CM users primarily suffered from migraines, arthritis and allergies [18]; no survey included specific questions regarding the use of CM for back pain.

This study has several objectives: to investigate the prevalence of $\mathrm{CM}$ use in patients visiting an academic pain center in Switzerland, to examine patients' perceptions of the effects of these therapies, to explore their knowledge of $\mathrm{CM}$, and to investigate patient-physician communication regarding $\mathrm{CM}$. A secondary objective is identifying factors associated with CM use for CLBP.

\section{Methods}

\section{Study design}

This cross-sectional study occurred from November 2014 to February 2015. Questionnaires were distributed by physicians during their encounters with every patient consulting for CLBP at the Pain Center at the Lausanne University Hospital in the French speaking part of Switzerland.

\section{Setting and participants}

Recruitment of participants for the study was conducted within the pain center at the Lausanne University Hospital. For a period of 8 weeks, at the end of each encounter with a cLBP patient, physicians gave the patient a printed questionnaire with a stamped envelope including the return address. Thus, questionnaires were given to all consecutive eligible cLBP patients during the time period of the study. At the beginning of the questionnaire, the goal of the study was explained to the participants, confidentiality was confirmed, and specific terms such as chronic LBP and the CM definition used for this study were explained. Patients were required to return the questionnaire within 3 weeks.

Inclusion criteria were patients consulting at our pain center for CLBP lasting longer than six months and who spoke fluent French. Our study considered pain to be chronic after six months, consistent with the definition of the American Academy of Pain Management [19]. Patients under 18, unable to understand written or verbal instructions to complete the questionnaire or considered unable to answer the questionnaire by medical or nursing staff (for example, suffering from serious psychiatric disease) were excluded.

It is worthy to note that the pain center were the study took place offered only conventional treatments at the time of the study, thus CM use could not have been increased due to a CM offer at the pain center.

\section{Variables}

We developed a 25-item questionnaire that was divided into three sections. The first section (seven items) explored socio-demographic data. The second section (five items) sought to describe the duration and burden of cLBP. The last section (13 items) inquired about the patient's knowledge, use of and perceptions regarding CM in the context of cLBP (see Additional file 1).

Self-reported knowledge regarding CM was evaluated with an item consisting of 21 sub-items assessing the 21 different $C M$ techniques presented in the questionnaire. For each technique, knowledge could reach a maximum of 3 points (from 0 points for "I do not know that technique" to 3 points for "I know this technique very well"). The knowledge score was the sum of the 21 items, resulting in a 63-point maximum score for the entire set of sub-items. 


\section{Data sources}

The questionnaire combined results from the literature search and discussions within our team but was primarily based on a previously published instrument [14]. We also adapted some of our questions from the American National Health Interview Survey (NHIS) [20]. The questionnaire was subjected to cognitive testing [21]. The goal was to determine how respondents interpreted the intent and meaning of survey questions and whether these responses matched the interpretations of the researchers. Cognitive interviews were conducted with ten volunteer cLBP patients and with ten healthy volunteers from the general public, all with a range of various socio-demographic characteristics [20]. The resulting modifications were conducted to enhance patients' comprehension of the questions. The protocol and the questionnaire were approved by the ethics committee of the Canton of Vaud.

\section{Statistical analysis}

Data quality and completeness (unusual values, consistency, missing values) were checked to ensure data quality. Categorical data were summarized by frequency and percentage and the mean $( \pm S D)$ for the age. Univariable logistic regression analyses were performed to identify factors associated with CM use for CLBP. The strength of the association was measured by the OR (Odds Ratio) and $p$-values. Knowledge regarding various CMs was assessed using the univariable Poisson regression model, and the strength of the association was measured by the IRR (Incidence Rate Ratio) and associated $p$-values. For both outcomes, CM use, and knowledge regarding various CM factors, outcomes at a level of $20 \%(p$-value $<0.20)$ were considered in a backward stepwise procedure to fit a multivariable model. Statistical analysis was conducted using Stata 14 software (StataCorp. 2015. Stata Statistical Software: Release 14. College Station, TX: StataCorp LP).

\section{Results}

Of the 238 eligible patients, 168 (response rate: 70.6\%) completed the questionnaire, 9 declined to participate and 61 did not return the questionnaire. Socio-demographic characteristics are described in Table 1.

Approximately half (46.9\%) of the participants had experienced cLBP for more than 5 years and 39\% for 1 to 5 years. Eighty-three percent had experienced LBP every day or nearly every day in the previous 6 months. On a 0 to 10 numeric-rating scale on which 0 indicated "not bothering at all" and 10 indicated "extremely bothering", level of discomfort was rated as a mean \pm SD of $7.3 \pm 1.9$.

CM had been used by $77.3 \%$ of the participants to specifically treat cLBP, with a median of 2 methods per person used (IQR: 4). Among CLBP CM users, the most
Table 1 Patients' socio-demographic characteristics $(N=168)$

\begin{tabular}{|c|c|}
\hline \multicolumn{2}{|l|}{ Age } \\
\hline Mean $( \pm S D)$ & $60( \pm 16.4)$ \\
\hline \multicolumn{2}{|l|}{ Sex } \\
\hline Male & $71(42.8)$ \\
\hline Female & $95(57.2)$ \\
\hline \multicolumn{2}{|l|}{ Origin } \\
\hline Swiss & $113(69.3)$ \\
\hline Other & $50(30.7)$ \\
\hline \multicolumn{2}{|l|}{ Educational level } \\
\hline Basic/apprenticeship & $88(59.1)$ \\
\hline Professional diploma/high school/college & $33(22.1)$ \\
\hline University & $28(18.8)$ \\
\hline \multicolumn{2}{|l|}{ Marital status } \\
\hline Single & $23(13.7)$ \\
\hline Married/civil partnership & $90(53.9)$ \\
\hline Divorced/separated & $38(22.8)$ \\
\hline Widower & $16(9.6 \%)$ \\
\hline \multicolumn{2}{|l|}{ Complementary medicine health insurance } \\
\hline Yes & $98(60.1)$ \\
\hline No & $58(35.6)$ \\
\hline Does not know & $7(4.3)$ \\
\hline \multicolumn{2}{|l|}{ Duration of pain } \\
\hline $1-12$ months & $23(14.3)$ \\
\hline $1-5$ years & $62(38.5)$ \\
\hline More than 5 years & $76(47.2)$ \\
\hline
\end{tabular}

Results are expressed in number of participants (percentage)

common therapies used were osteopathy (48.8\%), massage (45.2\%) and acupuncture (31.6\%). Therapies used and their perceived usefulness, rated on a 0 to 10 numeric rating scale ( 0 being useless and 10 being extremely helpful), are presented in Table 2. There was little variation in the perceived usefulness of the different therapies, with results ranging from 3.5 to 5.9 .

Concerning knowledge of CM therapies, the mean \pm SD score for knowledge of the $21 \mathrm{CM}$ types proposed in the questionnaire was $12.1 \pm 9.8$ points of 63 points. Specifically, the mean scores were 9 points $(S D=7.1)$ for men and 15 points $(S D=11)$ for women. The best-known method was osteopathy, followed by massage and acupuncture. Women were more likely to have a higher score than men. Most participants obtained information about CM through family and friends (62.5\%), followed by physicians (42.3\%) and the media (25.6\%). Adjusted IRR from multivariable analysis are shown in Table 3. Compared with respondents aged 21-48, respondents aged 49-59 had a better knowledge of CM. Being a woman, of Swiss nationality, and having health insurance 
Table 2 Complementary medicine used and its rated usefulness against chronic low back pain

\begin{tabular}{lll}
\hline CM therapies & Percentage of users & $\begin{array}{l}\text { Perceived usefulness } \\
(\text { mean } \pm \text { SD) }\end{array}$ \\
\hline Osteopathy & 48.8 & $5.4 \pm 2.7$ \\
Therapeutic massage & 45.2 & $5.9 \pm 2.5$ \\
Acupuncture & 31.6 & $3.8 \pm 3.2$ \\
Other & 21.5 & \\
Homeopathy & 14.9 & $3.83 \pm 2.5$ \\
Reflexology & 14.9 & $4.0 \pm 2.6$ \\
Aromatherapy & 10.7 & $4.2 \pm 2.8$ \\
Kinesiology & 9.5 & $5.1 \pm 3.0$ \\
Meditation & 8.9 & $4.8 \pm 2.8$ \\
Herbal medicine & 8.9 & $4.3 \pm 2.8$ \\
Reiki & 8.9 & $4.5 \pm 3.9$ \\
Yoga & 8.3 & $3.5 \pm 2.9$ \\
Magnetism & 6.0 & $4.7 \pm 3.6$ \\
Chinese herbs & 5.4 & $3.9 \pm 3.6$ \\
Hypnosis & 4.8 & $5.1 \pm 3.8$ \\
Shiatsu & 4.8 & $3.5 \pm 3.3$ \\
Sophrology & 4.8 & $3.9 \pm 2.5$ \\
\hline
\end{tabular}

a Usefulness was rated on a 0 to 10 scale $(0$ being useless and 10 being extremely helpful)

that covered CM were also predictors of greater knowledge of CM.

Regarding communication, the results indicated that if their physician proposed CM as a treatment for CLBP, $58.3 \%$ of the participants would be very likely and $18.6 \%$ would be somewhat likely to try CM. Of the participants, $45.2 \%$ reported that their physicians at the pain center had asked about using CM, and 16.5\% reported that their physicians had proposed including CM (primarily acupuncture) in the treatment strategy. Among patients who used CM at least once for their cLBP, $46.7 \%$ reported their CM use to their physicians, and in response, $55.6 \%$ of the physicians encouraged their patients to continue; $30.5 \%$ of physicians did not make any recommendation. Among the participants who did not discuss using $\mathrm{CM}$ with their physicians, the majority $(45.6 \%)$ said that the lack of communication was "because the physician did not ask me about it".

As a secondary objective, we identified the factors associated with CM use for CLBP. Respondents having CM health insurance coverage were more likely to use CM. Respondents having experienced cLBP for more than five years were more likely to use CM to treat their cLBP than respondents having experienced cLBP for one year or less. Respondents having a professional diploma or having attended high school/college were more likely than respondents with basic educational levels or apprenticeships to use CM for cLBP. However, it was not possible to fit any multivariable model for $\mathrm{CM}$ use for cLBP. Detailed results are shown in Table 4.

\section{Discussion}

More than three quarters of all participants used CM for cLBP at some point in their lives. In our sample, the typical cLBP patient using CM was a female approximately 60 years old, having a professional diploma or having attended high school/college. This greater use of $\mathrm{CM}$ and the profile of a typical CM user were also identified in a study on $\mathrm{CM}$ use in chronic headaches and CLBP [12].

The most common therapies used to treat cLBP were osteopathy, massage and acupuncture, followed by homeopathy and reflexology. In addition to chiropractic, those therapies were also the most common among patients identified in two recent studies of $\mathrm{CM}$ use for back pain $[22,23]$. For cLBP patients more specifically, a study investigated the use of and knowledge regarding five CM therapies (chiropractic, tai-chi, massage, acupuncture and meditation) by cLBP patients in the US [14]. That study's results indicated that approximately half of participants used chiropractic for cLBP, onequarter used massage, and approximately one-tenth used acupuncture and meditation. Our study showed higher usage rates for massage, acupuncture and meditation; however, both studies showed a preference for manual techniques and acupuncture. Another study on CM conducted in Austria and Germany on the same type of population indicated that patients mostly used thermotherapy, massage and acupuncture [12]. Our study did not include chiropractic use because chiropractic is considered a medical profession in Switzerland and not a CM therapy.

Our results have shown that the therapies that participants knew best were also the most used therapies. However, the perceived helpfulness of some less used and lesser-known therapies was rated higher than the therapies most commonly used. As described previously, the most used therapies were osteopathy, massage, acupuncture, and homeopathy; however, the highest rated were massage, osteopathy, hypnosis and kinesiology. In a study of five CMs used for cLBP (acupuncture, chiropractic, massage, meditation and tai chi), Sherman et al. [14] observed slightly higher rates of perceived helpfulness than within our study population for massage (6 compared with 7), acupuncture (4 compared with 5) and meditation (5 compared with 5 ). In a study among the US low back pain adult population, more than half of acupuncture, massage and yoga users considered those therapies as having great benefits [23]. According to the National Center for Complementary and Integrative Health $(\mathrm{NCCIH})$, spinal manipulation, acupuncture and massage may actually be beneficial in treating chronic 
Table 3 Poisson regression analysis of patients' knowledge regarding complementary medicine and associated factors

\begin{tabular}{|c|c|c|c|c|}
\hline \multirow[t]{2}{*}{ Variables } & \multicolumn{2}{|c|}{ Univariable analysis } & \multicolumn{2}{|c|}{ Multivariable analysis } \\
\hline & IRR $(95 \% \mathrm{Cl})$ & $p$-value & $\operatorname{IRR}(95 \% \mathrm{Cl})$ & $p$-value \\
\hline \multicolumn{5}{|l|}{ Sex } \\
\hline Female & $1.61(1.45-1.79)$ & $<0.001$ & $1.57(1.40-1.75)$ & $<0.001$ \\
\hline Male & 1 ref & - & 1 ref & - \\
\hline \multicolumn{5}{|l|}{ Age } \\
\hline $21-48$ & ref & - & ref & - \\
\hline $49-59$ & $1.23(1.09-1.39)$ & 0.001 & $1.19(1.05-1.35)$ & 0.005 \\
\hline $60-74$ & $0.65(0.56-0.76)$ & $<0.001$ & $0.67(0.58-0.78)$ & $<0.001$ \\
\hline $75-88$ & $0.72(0.62-0.85)$ & $<0.001$ & $0.64(0.55-0.75)$ & $<0.001$ \\
\hline \multicolumn{5}{|l|}{ Education } \\
\hline Basic/apprenticeship & ref & - & - & - \\
\hline Professional diploma/high school/college & $1.06(0.94-1.20)$ & 0.30 & - & - \\
\hline University & $1.03(0.90-1.18)$ & 0.65 & - & - \\
\hline \multicolumn{5}{|l|}{ Marital status } \\
\hline Single & ref & - & - & - \\
\hline Married/civil partnership & $0.97(0.84-1.13)$ & 0.76 & - & - \\
\hline Divorced/separated & $1.15(0.98-1.36)$ & 0.07 & - & - \\
\hline Widower & $0.95(0.74-1.21)$ & 0.68 & - & - \\
\hline \multicolumn{5}{|l|}{ Nationality } \\
\hline Other & ref & - & ref & - \\
\hline Swiss & $1.37(1.21-1.55)$ & $<0.001$ & $1.31(1.15-1.50)$ & $<0.001$ \\
\hline \multicolumn{5}{|l|}{ Complementary medicine health insurance } \\
\hline No & ref & - & ref. & - \\
\hline Yes & $1.19(1.07-1.32)$ & 0.001 & $1.12(1.00-1.25)$ & 0.03 \\
\hline
\end{tabular}

low back pain [24]. Results of RCTs and meta-analysis also indicated that some CMs such as meditation could be suggested as a treatment option to patients with cLBP $[25,26]$. Moreover, the American College of Physicians emitted guidelines for the treatment of cLBP which emphasizes on the use of noninvasive treatments such as yoga, acupuncture and tai-chi [10].

Patients having experienced cLBP for more than five years were 2.8 times more likely to have used $\mathrm{CM}$ for that condition than patients having experienced cLBP for one year or less, which may indicate that CM treatments are perceived as a late resort for patients with cLBP. This explanation was also suggested in a study among women with back pain in Australia [27].

Patients having CM health insurance coverage were significantly more likely to use CM for cLBP. This finding is consistent with the fact that in Switzerland, supplemental insurance often covers the cost of various CM treatments that are not reimbursed by the mandatory basic health insurance. Thus, it appears that the costs of CM may affect its use by cLBP patients. In addition, patients more interested in $\mathrm{CM}$ or who have had positive $\mathrm{CM}$ experiences may choose to acquire complementary coverage to support CM. Sherman [14] also observed that patients would be more likely to try $\mathrm{CM}$ if their primary care provider thought the treatment was reasonable and if $\mathrm{CM}$ came with no extra cost, or a $\$ 10$ co-pay, than if the patients had to pay for the entire treatment out of pocket.

Three-quarters of the participants were very or somewhat likely to try CM to treat their cLBP if their physicians suggested that treatment. A first step would most likely be to increase physicians' knowledge of $\mathrm{CM}$ and its effectiveness, particularly because most patients ultimately use $\mathrm{CM}$ but perhaps not always to the most useful treatments. As noted elsewhere, physicians mention the need to learn more about CM to adequately address patients' concerns [28]. This finding highlights the importance of physicians' obtaining knowledge regarding which $\mathrm{CM}$ should be recommended or not recommended in the treatment of cLBP. This statement is reinforced by the fact that nearly half of our participants 
Table 4 Summary data for users (Yes) compared with non-users (No) of complementary medicine for chronic low back pain

\begin{tabular}{|c|c|c|c|c|}
\hline & \multicolumn{4}{|c|}{ Complementary medicine use for chronic low back pain } \\
\hline & YES & NO & OR $(95 \% \mathrm{Cl})$ & ( $p$-value) \\
\hline & $(N=126)$ & $(N=37)$ & & \\
\hline Age (mean \pm SD) & $59( \pm 16.2)$ & $61( \pm 16.2)$ & $0.99(0.96-1.01)$ & 0.41 \\
\hline \multicolumn{5}{|l|}{ Sex } \\
\hline Male & $50(40.3 \%)$ & $19(51.4)$ & ref & \\
\hline Female & $74(59.7 \%)$ & $18(48.6)$ & $1.56(0.74-3.26)$ & 0.24 \\
\hline \multicolumn{5}{|l|}{ Origin } \\
\hline Other & $36(29.5 \%)$ & $13(36.1 \%)$ & ref & \\
\hline Swiss & $86(70.5 \%)$ & $23(63.9 \%)$ & $1.35(0.61-2.95)$ & 0.45 \\
\hline \multicolumn{5}{|l|}{ Educational level } \\
\hline Basic/apprenticeship & $66(55.5 \%)$ & $22(73.3 \%)$ & ref & \\
\hline Professional diploma/high school/college & $31(26 \%)$ & $2(6.7 \%)$ & $5.16(1.14-23-3)$ & 0.03 \\
\hline University & $22(18.5 \%)$ & $2(20 \%)$ & $1.22(0.43-3.4)$ & 0.70 \\
\hline \multicolumn{5}{|l|}{ Marital status } \\
\hline Single & 19 (15.2\%) & $3(8.8 \%)$ & ref & \\
\hline Married/civil partnership & $67(53.6 \%)$ & $10(58.8 \%)$ & $0.50(0.13-1.87)$ & 0.31 \\
\hline Divorced/separated & 29 (23.2\%) & $8(23.6 \%)$ & $0.57(0.13-2.43)$ & 0.45 \\
\hline Widower & $10(8 \%)$ & $3(8.8 \%)$ & $0.32(0.06-1.6)$ & 0.16 \\
\hline \multicolumn{5}{|l|}{ Complementary medicine health insurance } \\
\hline No & $40(32.5 \%)$ & $14(41.2 \%)$ & ref & \\
\hline Yes & $81(65.9 \%)$ & $17(50 \%)$ & $2.26(1.07-4.78)$ & 0.03 \\
\hline Does not know & $2(1.6 \%)$ & $3(8.8 \%)$ & & \\
\hline \multicolumn{5}{|l|}{ Pain duration } \\
\hline 1-12 months & $14(11.3 \%)$ & $9(24.4 \%)$ & ref & \\
\hline $1-5$ years & $48(38.7 \%)$ & $14(37.8 \%)$ & $2.2(0.78-6.15)$ & 0.13 \\
\hline More than 5 years & 76 (47.2\%) & $14(37.8 \%)$ & $2.84(1.02-7.88)$ & 0.04 \\
\hline
\end{tabular}

Associations between explanatory variables and outcomes were assessed using logistic regression model and expressed by the Odds-Ratio (OR), $95 \%$ confidence interval and $p$-value

obtained information on CM through a physician sometime in life and thus rely on them as a source of information on the matter. The guidelines of the American College of Physicians [10], which recommend various $\mathrm{CM}$ techniques for the management of cLBP could be an important step for improving physicians' knowledge of useful CM treatments. Furthermore, a survey conducted among healthcare professionals, including physicians, midwifes and nurses, showed that more than $90 \%$ of the respondents considered CM could be helpful in the treatment of chronic pain but that they lacked information to advise their patients [29].

Nearly half of the participants reported that their physicians at the pain center asked if they used CM, and nearly half of the CM users did not spontaneously admit such use to their physicians. A recent study [30] indicated that among women using CM for back pain, only one-third informed their general practitioners after using
CM. Overall, few studies investigated physician-patient communication in the context of CM for low back pain [22]. Lack of communication may be linked to physicians' lack of knowledge of CM [28]. Furthermore, it has been shown that in the context of cLBP, effective patient-professional communication strengthened the therapeutic partnership and helped support patient's self-management ability [31].

Our study had several limitations. First, the study was monocentric and thus may not reflect CM use by cLBP patients in other pain centers. In addition, cLBP patients who are seen at a pain center constitute a selection of complex refractory cases. However, our primary results, such as the prevalence of $\mathrm{CM}$ use, were comparable to other studies [12, 22]. Second, our study focused on knowing the prevalence of $\mathrm{CM}$ use since they first experienced cLBP and not the participants' current use of $\mathrm{CM}$ or use in the previous year, for example. Such 
measurements would potentially have shown less $\mathrm{CM}$ use; however, because our population comprised chronic pain patients and sought to determine the perceived effectiveness of the CM treatments, we chose to study their long-term use. Third, the number of participants was relatively low because the study calendar allowed only eight weeks of data collection. This limitation renders our results more difficult to generalize. Fourth, it is possible that the score of perceived helpfulness of some less used and lesser-known therapies would be lower once tried more widely. Further investigations on $\mathrm{CM}$ use in the context of cLBP on a larger population sample are necessary. Finally, patients more interested in CM may have participated more readily than patients who had no interest, resulting in potential self-selection and biased results and indicating an exaggerated $\mathrm{CM}$ use and knowledge.

\section{Conclusion}

CM was used by a majority of cLBP patients in the pain center surveyed. The results indicated that the most commonly used therapies were not necessarily the highest rated in terms of perceived usefulness.

Our results highlight the importance of accumulating more data on the effectiveness of CM for cLBP. Furthermore, these results underline the need to improve patient-physician communication on the matter of $\mathrm{CM}$ use. Integrative pain centers in which patients may obtain advice both on conventional and CM treatments should be developed to provide better support for patients with chronic pain.

\section{Additional file}

Additional file 1: Study questionnaire (in French). (DOCX $67 \mathrm{~kb}$ )

\section{Abbreviations}

CM: Complementary medicine; CLBP: Chronic low back pain; NHIS: American National Health Interview Survey; NCCIH: National Center for Complementary and Integrative Health

\section{Acknowledgements}

The authors thank Florence Degoumois for her contribution to the study. We wish to thank all participating patients as well.

\section{Funding}

This study was supported by a grant from the Swiss National Science Foundation (Special Program University Medicine 33CM30-140,339 to ID).

\section{Availability of data and materials}

The datasets generated during this study are available from the corresponding author upon a reasonable request.

\section{Authors' contributions}

PYR and ID conceived the study. ES, ID, BB and PYR developed the study design. ES, ID and PYR oversaw the trial. JD, BB and PYR drafted the manuscript. JD, PYR and MF analyzed the data. All authors read and approved the final manuscript.

\section{Competing interests}

The authors declare that they have no competing interests.

Consent for publication

Not applicable.

Ethics approval and consent to participate

The protocol and the questionnaire were approved by the ethics committee of the Canton of Vaud.

\section{Author details}

${ }^{1}$ Institute of Social and Preventive Medicine (IUMSP), Lausanne University Hospital, Route de la Corniche 10, 1010 Lausanne, Switzerland. Pain Center, Department of Anesthesiology, Lausanne University Hospital, Rue du Bugnon 46, 1011 Lausanne, Switzerland.

Received: 14 December 2016 Accepted: 24 March 2017

Published online: 04 April 2017

\section{References}

1. Andersson GB. Epidemiological features of chronic low-back pain. Lancet. 1999;354(9178):581-5.

2. Kanodia AK, Legedza ATR, Davis RB, Eisenberg DM, Phillips RS. Perceived benefit of complementary and alternative medicine (cam) for back pain: a national survey. J Am Board Fam Med. 2010;23(3):354-62.

3. Hoy D, March L, Brooks P, Blyth F, Woolf A, Bain C, Williams G, Smith E, Vos T, Barendregt J, et al. The global burden of low back pain: estimates from the global burden of disease 2010 study. Ann Rheum Dis. 2014;73(6):968-74

4. Henchoz Y. Lombalgies non spécifiques : Faut-il recommander l'exercice et les activités sportives ? Rhumatologie. 2011;286(10):612-6.

5. Wieser S, Horisberger B, Schmidhauser S, Eisenring C, Brügger U, Ruckstuhl A Dietrich J, Mannion AF, Elfering A, Tamcan O, et al. Cost of low back pain in switzerland in 2005. Eur J Health Econ. 2011;12(5):455-67.

6. Cherkin D, Sherman KJ. Conceptualization and evaluation of an optimal healing environment for chronic low-back pain in primary care. J Altern Complement Med (New York, NY). 2004;10(Suppl 1):171-8.

7. Breivik H, Collett B, Ventafridda V, Cohen R, Gallacher D. Survey of chronic pain in europe: prevalence, impact on daily life, and treatment. Eur J Pain. 2006;10(4):287.

8. Freburger JK, Holmes GM, Agans RP, Jackman AM, Darter JD, Wallace AS, Castel LD, Kalsbeek WD, Carey TS. The rising prevalence of chronic low back pain. Arch Intern Med. 2009;169(3):251-8.

9. Rosenberg El, Genao I, Chen I, Mechaber AJ, Wood JA, Faselis CJ, Kurz J, Menon M, O'rorke J, Panda M. Complementary and alternative medicine use by primary care patients with chronic pain. Pain Med. 2008;9(8):1065-72.

10. Qaseem A, Wilt TJ, Mclean RM, Forciea MA. Noninvasive treatments for acute, subacute, and chronic low back pain: A clinical practice guideline from the american college of physicians. Ann Intern Med. 2017;166(6): 430-437.

11. Reid R, Steel A, Wardle J, Trubody A, Adams J. Complementary medicine use by the australian population: a critical mixed studies systematic review of utilisation, perceptions and factors associated with use. BMC Complement Altern Med. 2016;16:176.

12. Gaul C, Schmidt T, Czaja E, Eismann R, Zierz S. Attitudes towards complementary and alternative medicine in chronic pain syndromes: a questionnaire-based comparison between primary headache and low back pain. BMC Complement Altern Med. 2011;11:89.

13. Barnes PM, Powell-Griner E, Mcfann K, Nahin RL. Complementary and alternative medicine use among adults: United states. Adv Data. 2002:2004(343):1-19.

14. Sherman KJ, Cherkin DC, Connelly MT, Erro J, Savetsky JB, Davis RB, Eisenberg DM. Complementary and alternative medical therapies for chronic low back pain: what treatments are patients willing to try? BMC Complement Altern Med. 2004:4:9

15. Chou R, Qaseem A, Snow V, Casey D, Cross Jr JT, Shekelle P, Owens DK Diagnosis and treatment of low back pain: a joint clinical practice guideline from the american college of physicians and the american pain society. Ann Intern Med. 2007;147(7):478-91. 
16. Vickers AJ, Cronin AM, Maschino AC, Lewith G, Macpherson H, Foster NE, Sherman KJ, Witt CM, Linde K, Acupuncture TC. Acupuncture for chronic pain: individual patient data meta-analysis. Arch Intern Med. 2012;172(19):1444-53.

17. Klein SD, Torchetti L, Frei-Erb M, Wolf U. Usage of complementary medicine in switzerland: results of the swiss health survey 2012 and development since 2007. PLoS One. 2015;10(10):e0141985.

18. Simoes-Wust AP, Rist L, Dettling M. Self-reported health characteristics and medication consumption by cam users and nonusers: A swiss cross-sectional survey. J Altern Complement Med (New York, NY). 2014;20(1):40-47.

19. Weiner RS. Pain management: A practical guide for clinicians, sixth edition. Boca Raton: CRC Press; 2001.

20. Stussman BJ, Bethell CD, Gray C, Nahin RL. Development of the adult and child complementary medicine questionnaires fielded on the national health interview survey. BMC Complement Altern Med. 2013;13:328,

21. Beatty PC, Willis GB. Research synthesis: the practice of cognitive interviewing. Pub Opin Q. 2007;71(2):287-311.

22. Murthy $V$, Sibbritt DW, Adams J. An integrative review of complementary and alternative medicine use for back pain: a focus on prevalence, reasons for use, influential factors, self-perceived effectiveness, and communication. Spine J. 2015;15(8):1870-83.

23. Ghildayal N, Johnson PJ, Evans RL, Kreitzer MJ. Complementary and alternative medicine use in the us adult low back pain population. Glob Adv Health Med. 2016;5(1):69-78.

24. Nccih. What is alternative and complementary medicine? 2016. https://nccih nih.gov/health/integrative-health. Accessed 15 July 2016.

25. Goyal M, Singh S, Sibinga EM, Gould NF, Rowland-Seymour A, Sharma R, Berger Z, Sleicher D, Maron DD, Shihab HM, et al. Meditation programs for psychological stress and well-being: a systematic review and meta-analysis. JAMA Intern Med. 2014;174(3):357-68.

26. La Cour P, Petersen M. Effects of mindfulness meditation on chronic pain: a randomized controlled trial. Pain Med. 2015;16(4):641-52.

27. Kirby ER, Broom AF, Sibbritt DW, Refshauge KM, Adams J. Health care utilisation and out-of-pocket expenditure associated with back pain: a nationally representative survey of australian women. PLoS One. 2013;8(12):e83559.

28. Corbin Winslow L, Shapiro H. Physicians want education about complementary and alternative medicine to enhance communication with their patients. Arch Intern Med. 2002;162(10):1176-81.

29. Aveni E, Bauer B, Ramelet A-S, Kottelat Y, Decosterd I, Finti G, Ballabeni P, Bonvin E, Rodondi P-Y. The attitudes of physicians, nurses, physical therapists, and midwives toward complementary medicine for chronic pain: a survey at an academic hospital. Explore (New York, NY). 2016;12(5):341-6.

30. Murthy V, Adams J, Broom A, Kirby E, Refshauge KM, Sibbritt D. The influence of communication and information sources upon decision-making around complementary and alternative medicine use for back pain among australian women aged 60-65 years. Health Social Care Community. 2015;25(1):114-122.

31. Fu Y, Mcnichol E, Marczewski K, Closs SJ. Patient-professional partnerships and chronic back pain self-management: a qualitative systematic review and synthesis. Health Soc Care Community. 2016;24(3):247-59.

\section{Submit your next manuscript to BioMed Central and we will help you at every step:}

- We accept pre-submission inquiries

- Our selector tool helps you to find the most relevant journal

- We provide round the clock customer support

- Convenient online submission

- Thorough peer review

- Inclusion in PubMed and all major indexing services

- Maximum visibility for your research

Submit your manuscript at www.biomedcentral.com/submit
Biomed Central 